\section{P136 (continued)}

select from among two drinks which were randomly rotated. Total participation included 315 (68\% Hispanic) individuals, between the ages of 18-25.

Measurable Outcome/Analysis: Data was analyzed using a conditional logistic regression model. Separate analyses were performed for low and high SSB consumers to determine factors participants take into consideration when making decisions about SSB consumption.

Results: Overall these participants prefer water and juice over regular soda $(P<.05)$. They expressed a preference for convenience (i.e., taking less time to get their drinks) and cost (i.e., paying less) $(P<.05)$. Moreover, participants did not want taxes from SSBs health programs $(P<.05)$.

Conclusion: The expressed preference for water over soda may result in a higher reduction in caloric intake if the price of SSBs is increased. This study suggests community and school-based, anti-SSB policies and education have been effective in modifying SSB attitudes and behaviors. Strengthening SSB policies may have long lasting effects on healthy behaviors.

Funding: University of California, Merced.

\section{P137 Food Insecure Students Identify Price as the Most Important Determinant of Their Food Choices}

Daniel Alvarez, University of Florida; Aseel El Zein, MS, LD, University of Florida; Melissa Vilaro, $P h D, M P H, C P H$, University of Florida; Sarah Colby, PhD, RDN, University of Tennessee; Karla Shelnutt, PhD, RDN, University of Florida; Wenjun Zhou, PhD, University of Tennessee; Melissa Olfert, $D P H, R D N$, West Virginia University; Tanya Horacek, PhD, $R D N$, Syracuse University; Geoffrey Greene, PhD, RDN, University of Rhode Island; Carol Byrd-Bredbenner, PhD, RD, FAND, Rutgers University; Jesse Morrell, PhD, University of New Hampshire; Adrienne White, PhD, RDN, University of Maine; Tandalayo Kidd, $P h D, R D N$, Kansas State University; Onikia Brown, PhD, RDN, Auburn University; Kendra Kattelmann, PhD, RDN, South Dakota State University; Anne Mathews, PhD, RDN, anne. mathews@ufl.edu, University of Florida, 572 Newell Dr, FSHN Bldg, Gainesville, FL 32611

Background: Food insecurity is a growing concern among US higher education institutions. Research is needed to understand the impact of food insecurity on food choice priorities when designing interventions for college students. Objective: To examine the factors that influence decisions about food between food secure (FS) and food insecure (FI) college students.

Study Design, Settings, Participants: Cross-sectional study among first year students from eight US universities $(\mathrm{N}=857)$.

Measurable Outcome/Analysis: Food choice priorities (14-item Likert scale survey and priority factor rankings) and food security status (USDA Adult Food Security Module). Independent samples t-tests comparing food choice priorities by student food security status.
Results: Food insecurity was prevalent with 19\% $(n=163)$ of students reporting inconsistent access to food in the past year. Compared to FS students, FI students rated price, perceived stress, and the ability to feel full as being significantly more important when making food decisions $(P<.05)$. Conversely, FI students rated convenience and a significant-other as being significantly less important influences on their food choices $(P<.05)$. Among FI students, price was the most important factor $(4.35 \pm 0.93)$, followed by taste $(3.92 \pm 1.09)$, convenience (3.88 \pm $1.05)$, the ability to feel full $(3.73 \pm 1.10)$, health $(3.71 \pm$ $1.02)$, and perceived stress $(3.06 \pm 1.32)$. Price was ranked as the primary factor influencing food decisions by $54 \%$ of FI students while only $13.4 \%$ reported health as their top priority.

Conclusion: Findings suggest that FI students are making decisions about food differently than FS students and that price is the most important determinant. Initiatives to address FI should consider and assess how the intervention impacts students' decisions about food.

Funding: None.

\section{P138 Increasing Access to the Special Supplemental Nutrition Program for Women, Infants \& Children Through Discount Variety Stores}

Victoria Galica, MA, VGalica@uncc.edu, University of North Carolina-Charlotte, 9201 University City Blvd, Charlotte, NC 28223; Lauren Wallace, DPH, University of North Carolina-Charlotte; Katelin Hudak, MID, University of North Carolina-Charlotte; Caitlan Webster, MA, University of North Carolina-Charlotte; Elizabeth Racine, $D P H$, University of North Carolina-Charlotte

Background: The Special Nutrition Assistance Program for Women, Infants, and Children (WIC) increases access to nutritious foods for low-income pregnant, postpartum, and breastfeeding women and their children under five. Participation in WIC has declined for the past six years. Discount variety stores (DVS) can be useful points of food access for low-income communities.

Objective: To identify facilitators and barriers to WIC implementation in multiple DVS locations. Identifying the facilitators and barriers associated with WIC implementation may lead to more successful program adoption, allowing more families to benefit from WIC and increase DVS revenues.

Study Design, Settings, Participants: We conducted in-depth interviews with 30 staff at corporate $(n=6)$, managerial $(n=22)$, and store clerk $(n=8)$ levels at ten DVSs in low-income communities in North Carolina. These stores implemented WIC over a 10-month pilot study to access WIC feasibility; nine stores were located in food deserts.

Measurable Outcome/Analysis: Interviews were coded, and an inductive approach was used to identify qualitative themes.

Results: All except one participant provided positive feedback about being involved in the WIC program. Many DVSs store employees had previous experience 


\section{P138 (continued)}

participating in the WIC program which gave them a good understanding of the WIC shopping experience. Previous WIC experience and proximity to store location for DVS customers were facilitators of WIC implementation. The primary barriers included limited choice in store products for customers, complicated or unclear labeling for WICeligible products, and difficulty training store employees to process WIC payments.

Conclusion: Most employees have a positive view of WIC but barriers related to product selection and training must be addressed to improve future WIC implementation. Notably, WIC's new electronic benefit transfer system (eWIC), which does not require as much detailed and manual employee training, should address several barriers to implementation. Future studies should evaluate implementation of eWIC in DVSs.

Funding: Robert Wood Johnson Foundation.

\section{P139 Student Use and Perceptions of a Campus Food Pantry at Appalachian State University}

Laura McArthur,PhD,RD, mcarthurlh@appstate.edu, Appalachian State University, 1179 State Farm Rd, Boone, NC 28608; Alisha Farris, PhD, RDN, Appalachian State University; Kimberly Fasczewski, PhD, Appalachian State University; Miranda Petrone, BS, Appalachian State University

Background: Food insecurity is a public health problem among US college students. Over 640 campuses have established food pantries as temporary solutions to improve this food deficit. A pantry was opened at Appalachian State University (App State) in 2016 that has not been assessed for student use and perceptions.

Objective: Measure student use and assess perceptions of the physical environment, food offerings, and customer service at the campus food pantry.

Study Design, Settings, Participants: Cross-sectional online survey of 40 App State students.

Measurable Outcome/Analysis: Descriptive procedures measured food security status, pantry use, and perceptions of pantry services, and identified associations between variables. Significance was $P<.05$.

Results: One thousand students were recruited, and 215 (21.5\%) submitted complete questionnaires. Food insecurity affected 91 (42.3\%) of students, of whom 35 (38.4\%) used the pantry. Pantry users were $28.9 \%$ males and $68.4 \%$ females and $34.2 \%$ freshmen/sophomores and $52.6 \%$ juniors/seniors. Reasons given by food insecure students for not using the pantry were "Others need it more" (65.9\%), "I have regular adequate access to food" (58.2\%), and "I feel embarrassed asking for help accessing food" $(40.7 \%)$. Frequency of pantry use ranged from only once (28.9\%) to once or twice/week (18.4\%). Products most frequently accessed were grain/cereal foods $(n=26)$, vegetables $(n=22)$, and snacks $(n=18)$. Benefits of pantry use included "Able to spend on other necessities" (60\%) and "Able to perform better on the job" (15\%). Pantry users perceived the physical environment and customer service most favorably and food offerings less favorably. Feelings when using the pantry included "Thankful" (65.8\%), "supported" (47.4\%), "Guilty" (47.4\%), and "anxious" (31.6\%).

Conclusion: Food insecure students appreciate and are benefited by the pantry and should be encouraged to use it until long-term solutions are implemented.

Funding: None.

\section{P140 The University of Arizona's SNAP-Ed Used the Health Food Pantry Assessment Tool to Identify Policy, Systems, and Environmental Changes in Food Pantries}

Lauren McCullough, MPH, laurenmccullough@email. arizona.edu, The University of Arizona, Shantz Building, Rm 118, 1177 E 4th St, PO Box 210038, Tucson, AZ 87521; Natalia Santos, MPH, The University of Arizona; Vanessa Farrell, PhD, RDN, The University of Arizona; Traci Armstrong-Floria, MS, RDN, The University of Arizona; Margine Bawden, M.Ed, The University of Arizona; Joyce Alves, MS, The University of Arizona; Scottie Misner, PhD, $R D N$, The University of Arizona

Objective: To use the Health Food Pantry Assessment Tool (HFPAT) to identify policy, systems, and environmental (PSE) changes in Arizona's food pantries.

Use of Theory or Research: The HFPAT was selected as an observational survey that measured the healthfulness of food pantry environments and provided PSE resources to guide food pantries and the University of Arizona Supplemental Nutrition Education - Program (UA SNAP-Ed) programming.

Target Audience: Four food pantries (Apache-2, Maricopa-2 Counties) that participated in SNAP-Ed completed the HFPAT.

Program Description: The SNAP-Ed sent the HFPAT in advance of site visits. Two Arizona SNAP-Ed staff independently completed the observational portions of the survey and results were compared. The survey was completed by interviewing the food pantry staff. Reports were generated using Qualtrics ${ }^{\circledR}$ and given to the food pantries. The HFPAT Resource Guide, which provides a resource for each section, was included.

Evaluation Methods: The HFPAT contained 69 questions divided into five sections: pantry location and entrance, food available to clients, policies of the food pantry, frozen chilled, dry storage and food safety, and services for clients. It provided a numeric score on a scale of 0-100; with a score of 100 signifying the healthiest food pantry environment.

Results: Four food pantries were assessed. The total scores ranged from 41 to 50 (mean: 46.25 out of 100). The food pantries' mean scores for each section were: a) 9.25 out of 15 possible points; b) 19.25 out of 57 possible points; c) 6 out of 12 possible points; d) 6.25 out of 10 possible points; and e) 4.5 out of 6 possible points.

Conclusions: The UA SNAP-Ed used the HFPAT to assist food pantries in identifying potential PSE interventions. This evaluation tool provided direction to the UA SNAP- 